\title{
VPLIV DRŽAVNIH MEJA NA DRUŽBENOGEOGRAFSKI RAZVOJ PREKMURJA
}

\author{
Ludvik Olas*, Božidar Kert**
}

Izvleček

UDK 911.3:341.222(497.12-18-04)

Državne meje so vedno imele negativen vpliv na razvoj Prekmurja. Prekinile so prometnice, ustvarile dvolastništvo in narodnostne manjšine.

Ključne besede: Meje, dvolastništvo, narodne manjšine, regionalni razvoj, Prekmurje

THE IMPACT OF STATE BORDERS ON THE SOCIO-GEOGRAPHIC DEVELOPMENT OF PREKMURJE

The state borders always had a negative impact on the development of Prekmurje. They have been creating dual owner structure and national minorities.

Key words: Borders, dual owner structure, national minorities, regional development, Prekmurje

Prekmurje spada med tiste slovenske pokrajine, kjer so državne meje najmočneje vplivale na družbeno-geografski razvoj. Te so ga v daljnji preteklosti odtrgale od naravno-geografsko enotnega slovenskega Pomurja. Kot regija z današnjim imenom se je rodilo po prvi svetovni vojni s saintgermansko in trianonsko mirovno pogodbo. Do takrat je bilo skozi tisočletje pod madžarsko državno upravo. Dolga ločitev od ostalih slovenskih pokrajin mu je v primerjavi s sosedstvom vtisnila nekatere družbeno-geografske posebnosti,ki pa danes vedno bolj izginjajo. Pomagati bi mu morali, da bi se bolj povezalo $\mathrm{z}$ ostalo Slovenijo. Tekoče stoletje mu v tem pogledu ni bilo naklonjeno. Državne meje ob njem so večkrat prelagali, odpirali in zapirali; komaj zgrajene mostove na Muri v vojni rušili in železniške proge ukinjali. Vse to je negativno vplivalo na gospodarski in populacijski razvoj. Že trianonska meja, o kateri so odločale velesile, je trgala gravitacijska zaledja od lokalnih regionalnih centrov, sekala prometne žile, ki pozneje niso nikoli več oživele ali pa jih v zadostni meri nadomestile druge. Pripomogla je k nastanku nekaterih mikroregij. K Avstriji je bilo priključenih pet pretežno slovenskih vasi, ki jih označujemo z imenom Radgonski kot. Ležijo med Muro, Kučnico in Radgono. Pred prvo svetovno vojno so z nazivom prekmurski Slovenci označevali vse slovensko govoreče prebivalstvo, ki je živelo na Madžarskem severno od Mure. Madžari so te po vzgledu Avstrijcev nazivali Vendi, pokrajino pa imenovali Vendvidek. Po odcepitvi Prekmurja pa so to ime prenesli na ozemlje ob Rabi, kjer še danes živijo Slovenci. Tako se je na Madžarskem, ob sedaj že zgodovinskem, rodil še mali

* Prof., višji predavatelj, Oddelek za geografijo, Pedagoška fakulteta Univerze v Mariboru, Koroška c. 160, 62000 Maribor, SLO

** Dr., izr. prof., Oddelek za geografijo, Pedagoška fakulteta Univerze v Mariboru, Koroška c. 160, 62000 Maribor, SLO 
geografski Vendvidek. Mi za to pokrajino uporabljamo naziv Slovensko Porabje ali kratko Porabje. Tudi Madžari so uradno uvedli naziv Rabavidek, kar v dobesednem prevodu pomeni pokrajina ob Rabi, $v$ strokovni literaturi pa še zasledimo za nas nesprejemljiv stari naziv Vendvidek.

\section{VPLIV DRŽAVNIH MEJA NA GOSPODARSKI RAZVOJ}

V prvi polovici tega stoletja je bilo kmetijstvo v Prekmurju po številu zaposlenih in narodnem dohodku prevladujoča gospodarska panoga. Male in srednje kmetije so bile pretežno samooskrbovalne s prvimi koraki usmerjanja v tržno živinorejo. To jim je omogočila bližina Avstrije. Pripadali so sicer k ogrskemu delu dvoglave monarhije, toda državna meja med njima ni predstavljala pomembnejše ovire pri menjavi gospodarskih dobrin.

Tržni viški prekmurskih kmetij so večinoma našli tržišče na avstrijski strani. Živino so kmetje gnali čez mejo več kilometrov daleč na najbližnjo železniško postajo. Cena živine je bila na avstrijski strani ugodnejša. Enako je veljalo tudi za poljedelske pridelke, zlasti za pšenico, ki je imela na madžarski strani močno konkurenco. Vse to je pripomoglo, da je v desetletjih pred prvo svetovno vojno zahodni del Madžarske ob avstrijski meji, tudi Prekmurje, napredoval hitreje, kot ostale agrarne pokrajine v državi. Že sredi preteklega stoletja (1846) so tu ustanovili Kmetijsko družbo Železne županije. Eden glavnih ciljev družbe je bilo prizadevanje, kako povečati mlečnost in pitanje goveje živine. Pri tem je imelo Prekmurje pomembno vlogo. Križali so namreč švicarsko simentalsko pasmo s posebno slovensko in tako se je razvila tako imenovana rdečelisasta pasma kot osnova za vzrejo, mlečnost in pitanje (Horvat, 1989). Ta pasma se je $\mathrm{v}$ drugi polovici preteklega stoletja razširila po vsem Čezdonavju. Njeno geografsko poreklo in žarišče pa sta še v naprej ostali dolini rek Mure in Rabe. Naravni pogoji za živinorejo so bili tu ugodni, v bližini na avstrijski strani pa tudi zanesljivo tržišče. Kmetijska družba je skrbela za pozitivno selekcijo živine. Pri tem so jo pri nakupu plemenskih samcev finančno podpirali domači veleposestniki.

Razmah živinoreje je vplival tudi na sestav kulturnih rastlin. Povečal se je delež krmnih rastlin, zlasti metuljnic (detelja, lucerna...). Opisani razvoj je zajel predvsem zahodni obmejni del Prekmurja.

Relativno zaprta meja med Avstrijo in Kraljevino SHS po pvi svetovni vojni je ta trend razvoja zaustavila. Obmejni prebivalci so si, nekoč vajeni prostih prehodov, pomagali z ilegalnimi prehodi in nakupi, kar je dobilo značaj tihotapstva. To obliko "oskrbe" je nova oblast preganjala. Posledice zaprte meje nam ilustrira naslednja tabela. Številke v njej se nanašajo na zahodni del Prekmurja, ki je pred vojno pripadal k Železni županiji, po vojni pa k srezu Murska Sobota. 
Tab. 1: Število konj, govedi in prašičev v zahodnem delu Prekmurja Zahl der Pferde, Rinder und Schweine in western Teil von Prekmurje

\begin{tabular}{cccc}
\hline Leto & Konji & Govedo & Prašiči \\
\hline 1869 & 3263 & 10066 & 11616 \\
1895 & 3208 & 22450 & 22162 \\
1938 & 2500 & 21700 & 20400 \\
\hline
\end{tabular}

Vir: Horvat, 1989; Krajevni leksikon, 1937

Trend rasti števila goveje živine in prašičev, ki je v zadnjem četrtletju preteklega stoletja izkazoval stoodstotno rast, se je popolnoma zaustavil in obrnil celo $\mathrm{v}$ negativno smer. $\mathrm{K}$ temu je prispevala tudi gospodarska kriza. Vojni čas in povojno nasilno združevanje kmetij pa sta dodali svoje. Prebivalstvo si je množično iskalo druge vire preživljanja. Zatekalo se je k sezonskemu zaposlovanju in izseljevanju. Deset tisoč in več jih je vsako leto delalo v tujini (Nemčija, Francija, Vojvodina in drugje). V resnici jih je bilo še več, ker se nekateri pozimi niso vračali in jih uradna statistika naslednje leto ni zajela. Borza dela v Murski Soboti je samo v Nemčijo odposlala leta 19396308 delavcev (Olas, 1956).

\section{VPLIV DRŽAVNIH MEJA NA RAZVOJ PROMETA IN POVEZANOST PREKMURJA Z ZALEDJEM}

Ugodne danosti za razvoj prometa v dolini reke Mure na območju Prekmurja v preteklosti niso bile izkoriščene. Reka povezuje alpsko notranjost s Panonsko nižino, to je dve po naravnih pogojih in gospodarski proizvodnji različni pokrajini. Menjava gospodarskih dobrin bi ob normalnih pogojih pospeševala tudi razvoj prometnih zvez. To pa so v preteklosti zavirale državne meje, ki so dolino sekale v prečni smeri. Skozi stoletja, zlasti pa pred dualizmom, je meja ob Kučnici ločila Avstrijo od Madžarske. Po prvi svetovni vojni pa se je na njo naslonila in nadaljevala po Muri državna meja med Jugoslavijo in Avstrijo. S trianonsko mirovno pogodbo pa je bila potegnjena prečno čez dolino Mure meja pri Lendavi med Jugoslavijo in Madžarsko. Naslonila se je na spodnji tok Ledave in izliv Krke v Muro. To je v zadnjih letih dopolnila še državna razmejitev med Slovenijo in Hrvaško, ki se nadaljuje na desni strani Mure. Ti dve prečni politični pregraji sta v preteklosti in tudi danes zavirali razvoj prometa $v$ podolžni smeri. Tisočletna državna meja na Muri pa je tudi pripomogla $\mathrm{k}$ temu, da do prve svetovne vojne čez njo na slovenskem območju ni bil zgrajen noben most.

Neugodna politična lega je negativno vplivala na povezavo z zaledjem tudi $v$ ostalih smereh. Razmere so se do določene mere izboljšale $\mathrm{v}$ času dualizma. Leta 1865 je bila zgrajena železniška zveza med Gyorom, Szombathelyem in Gradcem, leta 1890 je dobila železnico Lendava in leta 1907 še Murska Sobota. S krajšo zamudo je bilo tako Prekmurje priključeno na madžarsko železniško omrežje. Sedemnajstletna prednost Lendave se odraža tudi v 
zunanjem videzu mesta. Je edino naselje v Prekmurju, ki ima v starejšem mestnem jedru urbani videz. Posodobljena prometna infrastruktura in bližina Avstrije z odprto mejo sta pripomogli, da je imel zahodni obmejni del Madžarske $v$ vsem državnem okviru $\mathrm{v}$ času pred prvo svetovno vojno relativno najhitrejšo gospodarsko rast (Horvat, 1989). Ta se je odražala v rasti mest (Szombathely), v razvoju neagrarnih dejavnosti (Monošter z nemškim kapitalom) in v napredovanju kmetijstva. Ta sveži obmejni veter se je čutil tudi v Prekmurju. Najprej, kakor smo že rekli, v Lendavi, nato z dotokom židovskega kapitala tudi v Murski Soboti in v razvoju kmetijstva.

Nove državne meje so po prvi svetovni vojni, s svojo zaprtostjo in prekinitvijo prometnih zvez, tak razvoj zaustavile. Prekmursko gospodarstvo se je zaradi slabe prometne povezave le počasi navezovalo na Slovenijo. Murska Sobota je dobila železniško zvezo z Ljutomerom šele leta 1924, cestni most čez Muro pri Petanjcih pa je bil zgrajen avgusta 1940, aprila naslednje leto pa je bil ob umiku jugoslovanske vojske porušen. Goričko je imelo železniško zvezo s Slovenijo le slabih 40 let, potem ko so mu leta 1963 progo zaradi nerentabilnosti državnih železnic ukinili. Pri popisu prebivalstva zato nekatere vasi severnega Goričkega leta 1971 že izkazujejo reagrarizacijo. V zameno za železniško progo je bila Goričkemu obljubljena sodobna asfaltirana cesta. To obljubo Slovenija še dolguje. $Z$ osamosvojitvijo Slovenije sta za Prekmurje postala aktualna dva prometna projekta. To je obnova in posodobitev goričke železnice in njena priključitev na madžarsko železniško omrežje pri Monoštru. Služila bi naj predvsem tovornemu prometu v navezavi s pristaniščem v Kopru. Drugi projekt pa je povezan z izgradnjo avtomobilske ceste, ki bi naj prečkala jugovzhodni del Prekmurja v bližini Lendave. V navezavi Slovenije z ostalimi državami vzhodne Evrope je prehodnost Prekmurja pridobila na pomenu. Paziti moramo, da pri tem lokalne interese ne bi popolnoma zanemarili. Državne meje so negativno vplivale na razvoj lokalnega cestnega omrežja. Železna zavesa je po vojni kot simbol politične pregraje omejevala Prekmurje na zahodni-avstrijski strani. Takrat je na srečo le za krajše obdobje prekinila vse lokalne cestne zveze s sosedo. Po letu 1948 so jo premaknili na vzhod in je cela desetletja obrobljala vzhodni del Prekmurja. Zaprla je vse cestne zveze z Madžarsko. Posledice so bile usodne in se čutijo še danes. Do leta 1948 je bilo v Prekmurju ob madžarski državni meji devet mejnih prehodov, danes pa so samo štirje. Dva od teh (Martinje, Pince) so odprli pred kratkim.

Zaprta meja je bila usodna zlasti za obmejne predele z Madžarsko, ki so gospodarsko nazadovali in se populacijsko praznili. Stiki med sorodniki na obeh straneh meje so prenehali. Madžarska narodnost, ki živi na naši strani meje je izgubila stik z matičnim narodom. Dostop do nepremičnin na eni in drugi strani je bil onemogočen. Pri nas so zemljo madžarskim dvolastnikom obdelovali sorodniki in za njih plačevali tudi davke. Bili so pa tudi primeri, ko je obdelovalna zemlja popolnoma opustela in zarastla z grmičevjem. Na madžarski strani je šel razvoj v drugačno smer. Kolektivizacija kmetijskih zemljišč je zabrisala meje privatnih parcel. Te so se ohranile le $\mathrm{v}$ tistih obmejnih predelih, kjer zaradi neugodnih naravnih danosti do združevanja ni prišlo in je ostala zemlja $v$ individualni lasti. To velja v celoti za Slovensko Porabje. 
Slika 1: Odprtost državnih meja ob Prekmurju

Die Grenzuebergaenge im Bereich von Prekmurje in Slowenien

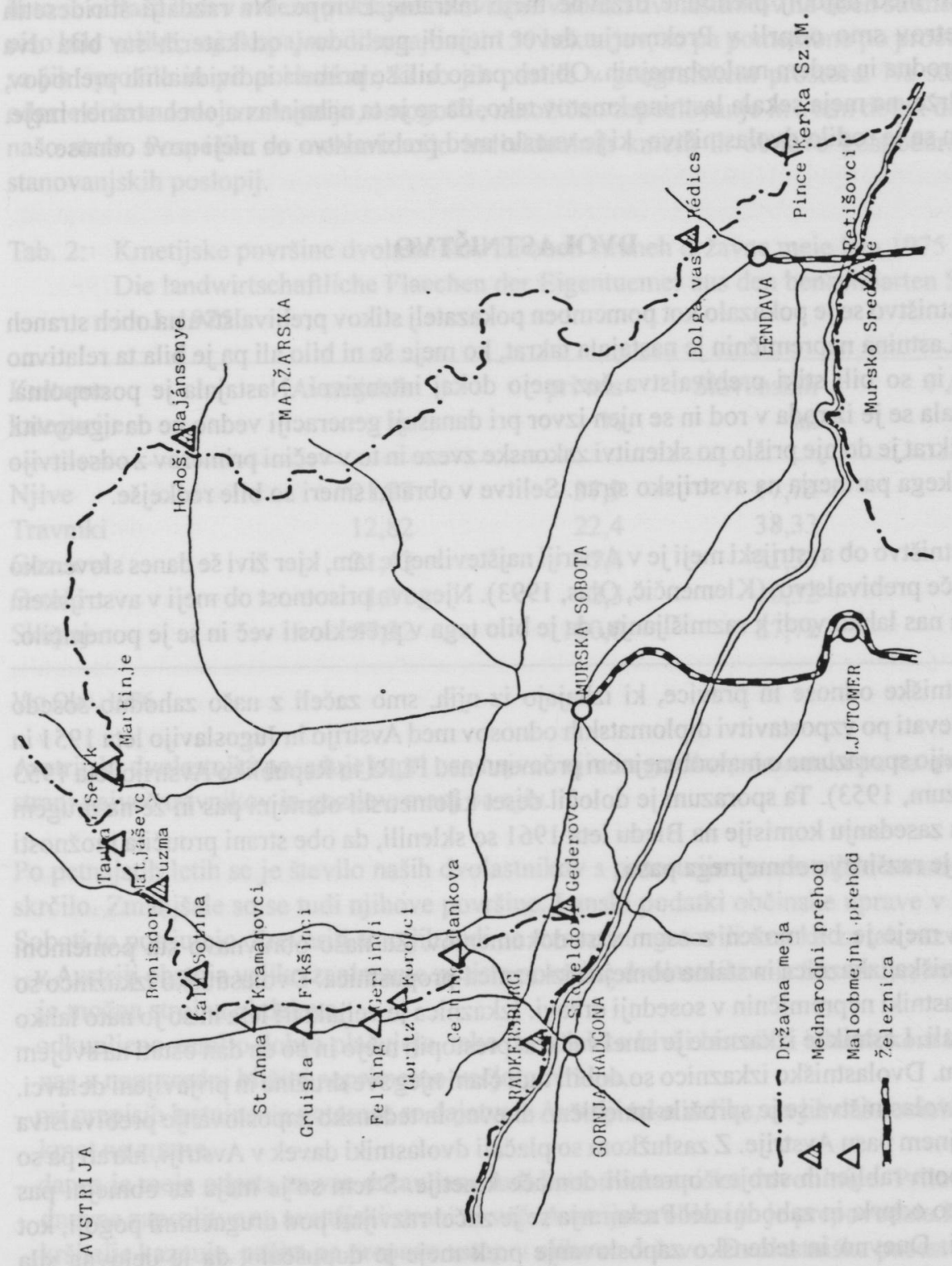


Manj opazne so bile posledice železne zavese ob avstrijski meji, kjer je ta delovala krajši čas. Po letu 1953 smo skupaj z Avstrijci to mejo odprli do take mere, da smo jo upravičeno uvrščali med najbolj prehodne državne meje takratne Evrope. Na razdalji štiridesetih kilometrov smo odprli v Prekmurju devet mejnih prehodov, od katerih sta bila dva mednarodna in sedem maloobmejnih. Ob teh pa so bili še primeri individualnih prehodov, ko je državna meja sekala lastnino kmetov tako, da se je ta nahajala na obeh straneh meje. Ob tem se je rodilo dvolastništvo, ki je vneslo med prebivalstvo ob meji nove odnose.

\section{DVOLASTNIŠTVO}

Dvolastništvo se je pokazalo kot pomemben pokazatelj stikov prebivalstva na obeh straneh meje. Lastnina nepremičnin je nastajala takrat, ko meje še ni bilo ali pa je bila ta relativno odprta in so bili stiki prebivalstva čez mejo dokaj intenzivni. Nastajala je postopoma. Prenašala se je iz roda $v$ rod in se njen izvor pri današnji generaciji vedno ne da ugotoviti. Največkrat je do nje prišlo po sklenitvi zakonske zveze in to $v$ večini primerov $z$ odselitvijo zakonskega partnerja na avstrijsko stran. Selitve v obratni smeri so bile redkejše.

Dvolastništvo ob avstrijski meji je v Avstriji najštevilnejše tam, kjer živi še danes slovensko govoreče prebivalstvo. (Klemenčič, Olas, 1993). Njegova prisotnost ob meji v avstrijskem zaledju nas lahko vodi $\mathrm{k}$ razmišljanju, da je bilo tega $\mathrm{v}$ preteklosti več in se je ponemčilo.

Dvolastniške odnose in pravice, ki izhajajo iz njih, smo začeli z našo zahodno sosedo uresničevati po vzpostavitvi diplomatskih odnosov med Avstrijo in Jugoslavijo leta 1951 in sklenitvijo sporazuma o maloobmejnem prometu med FLRJ in Republiko Avstrijo leta 1953 (Sporazum, 1953). Ta sporazum je določil deset kilometrski obmejni pas in že na drugem rednem zasedanju komisije na Bledu leta 1961 so sklenili, da obe strani proučila možnosti nadaljnje razširitve obmejnega pasu.

Prestop meje je bil možen z osem vrst dokumentov. Za našo obravnavo sta pomembni dvolastniška izkaznica in stalna obmejna izkaznica-propustnica. Dvolastniško izkaznico so dobili lastniki nepremičnin v sosednji državi. Izkaznica je veljala tri leta in so jo nato lahko podaljšali. Lastnik te izkaznice je smel večkrat presiopiti mejo in po en dan ostati na svojem posestvu. Dvolastniško izkaznico so dobili tudi člani njegəve družine in prijavljeni delavci. Preko dvolastništva se je sprožilo množično dnevno in tedensko zaposłovanje prebivaistva v obmejnem pasu Avstrije. Z zaslužkom so plačali dvolastniki davek v Avstriji, hkrati pa so z nakupom rabljenih strojev opremili domače kmetije. S tem se je meja za cbmejni pas praktično odprla in zahodni del Prekmurja se je začel razvijati pod drugačnimi pogoji, kot vzhodni. Dnevno in tedensko zaposlovanje prek meje je dopuščalo, da je delovna sila stanovala na domu. Vsak je svoje delo na mali kmetiji čimprej opravil in preostali čas izkoristil v Avstriji. Latentna delovna sila, ki je bila na malih kmetijah Prekmurja vedno prisotna, se je v zahodnem obmejnem delu za nekaj časa aktivno sprostila. Tudi del generacije je vtem videl bodočnost in ostal na kmetiji. Teh možnosti ob zaprti madžarski meji ni bilo. 
Tudi od tu je prebivalstvo odhajalo na sezonsko delo $\mathrm{v}$ tujino in pogosto ostalo tam več let ali se pa sploh ni vrnilo. Obmejna pokrajina se je praznila tu hitreje. Kmetije so propadale in to se odraža tudi v videzu pokrajine. Površine v rokah dvolastnikov na obeh straneh meje niso bile velike, saj skupaj ne dosegajo niti 150 hektarjev, so pa pomembne po procesih, ki so jih sprožile in po posledicah, ki so jih pustile v geografskem prostoru. Na stežaj so odprle državno mejo z Avstrijo, omogočile množično zaposlovanje in s tem dotok deviz na našo stran. Pospešile so mehanizacijo individualnih kmetij in obnovo gospodarskih in stanovanjskih poslopij.

Tab. 2: Kmetijske površine dvolastnikov na obeh straneh državne meje leta 1975

Die landwirtschaftliche Flaechen der Eigentuemer aus den benachbarten Staaten im J. 1975

\begin{tabular}{lrrrr}
\hline $\begin{array}{l}\text { Kulturne } \\
\text { kategorije }\end{array}$ & $\begin{array}{r}\text { Avstrijskih } \\
\text { ha }\end{array}$ & $\begin{array}{r}\text { pri nas } \\
\%\end{array}$ & $\begin{array}{r}\text { Slovenskih } \\
\text { ha }\end{array}$ & $\begin{array}{r}\text { v Avstriji } \\
\%\end{array}$ \\
\hline Njive & 21,77 & 37,9 & 17,74 & 20,7 \\
Travniki & 12,82 & 22,4 & 38,33 & 43,7 \\
Gozdovi & 21,42 & 37,4 & 31,33 & 35,7 \\
Ostalo & 1,31 & 2,3 & 0,32 & 0,4 \\
Skupaj & 57,32 & 100,0 & 87,72 & 100,0 \\
\hline
\end{tabular}

Vir: Olas, 1976.

Avstrijski dvolastniki posedujejo pri nas največ njiv in gozdov, slovenski pa na avstrijski strani največ travnikov in gozdov, manj pa njiv.

Po petnajstih letih se je število naših dvolastnikov s posestvijo na avstrijski strani močno skrčilo. Zmanjšale so se tudi njihove površine. Lanski podatki občinske uprave v Murski Soboti to potrjujejo. Preverili smo jih tudi na terenu in ugotovili vzroke za tak razvoj:

- v Avstriji obstoja veliko zanimanje za tiste površine dvolastnikov iz Slovenije, na katerih je možna strojna obdelava,

- odkupljeno zemljo dobro plačujejo, tako da si lahko bivši lastnik z izkupičkom kupi pri nas v neposredni bližini neprimerno večjo površino,

- pri prepisih lastnine na potomce so dajatve $v$ Avstriji tako velike, da jih naš socialno šibki kmet ne zmore,

- danes je meja odprta za vse državljane tudi brez dvolastniške dovolilnice. Priložnostne dnevne zaposlitve na avstrijski strani ni več. Avstrijska oblast jo je prepovedala.Domače kršitelje kaznuje, našim pa prepove vstop v njihovo državo. Dvolastniška posest tako ne prinaša več nobene prednosti. 


\section{LITERATURA IN VIRI}

Horvat, F., 1989, Zgodovina gospodarstva v delu Prekmurja, ki je pripadalo k Železni županiji (1828-1910). Časopis za zgodovino in narodopisje, 1989, št. 60, zv. 2, str. 177186.

Olas, L., 1956, Sezonsko zaposlovanje prekmurskega prebivalstva, Geografski vestnik, Ljubljana 1955-56, str. 176-208.

Klemenčič M., Olas L., 1993, Demografske strukture prebivalstva na skrajnem jugu avstrijske Štajerske ob slovensko avstrijski meji. Mednarodni avstrijsko-slovenski simpozij, Maribor.

Sporazum o ureditvi maloobmejnega prometa med FLRJ in Republiko Avstrijo, 1953. Olas, L., 1976, Dvolastništvo - dejavnik v razvoju Prekmurja kot obmejne regije, Geografski vestnik, št. 68, Ljubljana, str. 151-155.

\section{EINFLUSS DER STAATSGRENZEN AUF DIE GESELLSCHAFTLICHE UND GEOGRAPHISCHE ENTWICKLUNG VON PREKMURJE}

\section{Zusammenfassung}

Prekmurje, die Landschaft am linken Ufer der Mur, ist von der oesterreichischen, ungarischen und kroatischen Staatsgrenze umkreist. Von dem uebrigen Slowenien wird es durch die Mur getrennt, worueber eine Eisenbahn- und drei Strassenverbindungen verlaufen Die Grenzlage und die mehrmalige Versetzung der Staatsgrenzen haben hochgradige Folgen in der wirtschaftlichen und gesellschaftlichen Entwicklung hinterlassen.

Vor dem I. Weltkrieg war Prekmurje ein ganzes Jahrtausend lang unter der ungarischen Staatsverwaltung. Durch den Trianon-friedensvertrag (1919) und durch die Bestimmung der Staatsgrenze zwischen Jugoslawien und Ungarn wurde Prekmurje zum Koenigreich SHS (von Serben, Kroaten und Slowenen) bzw. zu Slowenien angeschlossen. Die neue Staatsgrenze unterbrach fast alle Verkehrswege mit dem bisherigen Hinterland. Bei Hodoš und bei Dolga vas wurden zuerst die Eisenbahnlinie unterbrochen, spaeter aber auch alle wichtigsten Strassenverbindungen.

Vor allem wurde die Landwirtschaft betroffen, die hier als Hauptwirtschaftszweig gilt. Die Landwirte von Prekmurje verkauften naemlich ihre Viehzucht- und Obstbaumarktueberschuesse in der Zeit der oesterreichisch-ungarischen Monarchie vor allem in Oesterreich, denn hier bestand danach ein groesserer Bedarf als in Ungarn, das vor allem ein Agrarland war. Der Verlust der oesterreichischen Maerkte war am starken Sinken an der Zahl der Rinder und Schweine zu spueren. Der Ausfall des Einkommens, womit die Landwirte ihre Bauerhoefe aufrechterhalten konnten, half auch bei dem Aufrechterhalten der altertuemlichen Landschaft. Die Haeuser aus Holz und die Daecher aus Stroh beherrschten noch lange die Dorfidylle. 
Die neuen Staatsgrenzen griffen auch in den Bereich der Beschaeftigung der Bevoelkerung stark ein. Die Beschaeftigung in den nichagrarischen Bereichen hoerte auf, ebenso die Beschaeftigung auf den ungarischen Grossgrundbesitzen. Das verhalft zur Ausweitung der Saisonbeschaeftigung in der Vojvodina, in Deutschland, Frankreich und anderswo. Um ueberleben zu koennen, nehmen die Saisonarbeiter auch die schwierigsten Arbeiten an.

Durch die neue Staatsgrenze verblieb auch die slowenische Volksminderheit in Porabje in Ungarn. Nach der amtlichen ungarischen Statistik gab es damalsin Porabje ungefaehr 5000 Slowenen, bis heute wurde nur noch die Haelfte erhalten. Auf der slowenischen Seite blieben ungefaehr 10.000 Ungarn, deren Zahl sich um etwa 20-25\% reduziert hatte.

An den Staatsgrenzen entstanden Doppeleigentuemer: slowenische in Oesterreich und Ungarn, oesterreichische und ungarische in Slowenien. Das Eigentum und die Rechte der Doppeleigentuemer an der oesterreichisch-slowenischen Staatsgrenze wurden definiert und realisiert, denn das ermoeglichte die offene Staatsgrenze. Im Gegenteil war die slowenischungarische Staatsgrenze lange geschlossen, die Kleingrenzuebergaenge sind aber auch noch heute eine Raritaet. Im besten Fall verlaengerte sich der Weg zum Anbauen des Landes wesentlich.

Durch das Einengen von Grossgrundbesitzen auf dem sozialistischen Sektor, ging das Eigentum unserer Staatsbuerger in Ungarn praktisch verloren.

Nach dem Zusammenbruch von Jugoslawien bekam Prekmurje im Sueden noch die Staatsgrenze mit Kroatien. Diese ist noch nicht eingezeichnet, es zeigen sich aber schon jetzt Probleme im Verhaeltniss zu Liegenschaften, zur Beschaeftigung der Bevoelkerung und zu sonstigen Bereichen.

Im Rahmen der beiden Jugoslawien zeigte Zentralslowenien zu wenig Interesse an Prekmurje. Es wurde zu wenig getan, damit Prekmurje mit dem uebrigen Slowenien verbunden werden koennte. Noch mehr - Slowenien brach sogar zwei bedeutende Eisenbahnlinien ab, ohne das Versprechen zu erfuellen, diese durch moderne Verkehrsstrassen zu ersetzen. 